\title{
Gender-specific determinants of asthma among U.S. adults
}

Rebecca Greenblatt ${ }^{1 \dagger}$, Omar Mansour ${ }^{2 \dagger}$, Edward Zhao $^{1}$, Michelle Ross ${ }^{1}$ and Blanca E Himes ${ }^{1 *}$

\begin{abstract}
Background: Asthma, a chronic respiratory disease affecting over 18.7 million American adults, has marked disparities by gender, race/ethnicity and socioeconomic status. Our goal was to identify gender-specific demographic and socioeconomic determinants of asthma prevalence among U.S. adults using data from the Behavioral Risk Factors Surveillance System (BRFSS) and the National Health and Nutrition Examination Survey (NHANES).

Methods: Gender-specific regression analyses were performed to model the relationship between asthma prevalence with age, race/ethnicity, income, education level, smoking status, and body mass index (BMI), while taking into account the study designs.

Results: Based on BRFSS data from 1,003,894 respondents, weighted asthma prevalence was 6.2\% in males and 10. $6 \%$ in females. Asthma prevalence among grade 2 obese and grade 3 obese vs. not overweight or obese women was 2.5 and 3.5 times higher, respectively, while that in men was 1.7 and 2.4 times higher; asthma prevalence among current vs. never smoker women was 1.4 times higher, while that in men was 1.1 times higher. Similar results were obtained with NHANES data from 13,364 respondents: asthma prevalence among grade 2 obese and grade 3 obese vs. not overweight or obese respondents was 2.0 and 3.3 times higher for women, though there was no significant difference for men; asthma prevalence among current vs. never smokers was 1.8 times higher for women and not significantly different in men. Asthma prevalence by race/ethnicity and income levels did not differ considerably between men and women.
\end{abstract}

Conclusions: Our results underscore the importance of obesity and smoking as modifiable asthma risk factors that most strongly affect women.

Keywords: Adult asthma, Asthma, Obesity, Smoking

\section{Background}

Asthma, a chronic obstructive lung disease characterized by variable airflow limitation and airway hyperresponsiveness, affects over 25.7 million Americans, including 18.7 million adults [1]. Women are disproportionately affected by asthma and adults are more likely to die from asthma than children [2]. The mechanisms underlying the gender difference in asthma prevalence are not known but hormonal and/or lung capacity differences between men and women have been proposed as contributing factors $[3,4]$. While gender is not a modifiable

\footnotetext{
*Correspondence: bhimes@upenn.edu

${ }^{\dagger}$ Equal contributors

'Department of Biostatistics and Epidemiology, University of Pennsylvania,

219 Blockley Hall, 423 Guardian Drive, Philadelphia, PA 19104, USA

Full list of author information is available at the end of the article
}

risk factor, a better understanding of gender-specific factors that lead to increased asthma in women would result in therapies or interventions that reduce disparities.

Asthma prevalence and exacerbation disparities by race/ ethnicity and socioeconomic status are also a well-known problem in the US [5-7]. Factors contributing to them include non-modifiable factors such as differences in genetic ancestry [8-10], and modifiable factors such as poor health, disease risk factors, medication non-adherence, health literacy and limited access to health care due to social, economic and environmental disadvantages [6, 11, 12]. Racial/ ethnic minority groups in the U.S. disproportionately fall within low socioeconomic status categories, resulting in difficulty separating health factors that are heritable vs. socioeconomic and environmental ones [13, 14]. According to 
2013 American Community Survey data, while racial/ethnic minorities made up $40 \%$ of all working families, they accounted for $58 \%$ of low-income families, and were twice as likely to be poor or low-income compared to nonHispanic whites [15]. Understanding the contribution of modifiable vs. non-modifiable factors that influence asthma is challenging but important to reduce disease disparities.

The Behavioral Risk Factors Surveillance System (BRFSS) is a cross-sectional telephone survey of individuals greater than 18 years old that has collected data for over 30 years to measure behavioral risk factors that link to chronic and preventable diseases [16]. The survey is conducted by state health departments in conjunction with the Centers for Disease Control \& Prevention (CDC) and includes the 50 U.S. states, the District of Columbia, and the U.S. territories of Guam, Puerto Rico, and the Virgin Islands. BRFSS data, whose quality is high, reliable and valid $[17,18]$, has been used to study disease trends and factors related to them, including obesity [19], cigarette smoking [20], binge drinking [21], and influenza vaccination rates [22]. Previous studies have also used BRFSS data to study asthma by identifying associated demographic factors with data from the years 2000 and 2009-2010 [23, 24], and finding that frequent mental distress [25] and poor self-rated physical and mental health [26] are more common among respondents with asthma than those without it.

The National Health and Nutrition Examination Survey (NHANES) is a CDC-led cross-sectional study designed to assess the health and nutritional status of adults and children in the U.S [27]. Highly trained personnel conduct extensive in-person household interviews and perform physical exams in mobile examination centers to obtain detailed information for enrolled subjects. Recruitment takes place via a complex probability cluster design to ensure samples are representative of the civilian, noninstitutionalized U.S. population. NHANES data has been used to understand asthma by studying its relationship with variables such as eosinophil counts, obesity and response to poor air quality [28-30], and to obtain reference distribution curves for measures such as exhaled nitric oxide [31].

Here, we used BRFSS data of over 1 million individuals and NHANES data of 13,364 individuals for the years 2007-2012 to better understand gender-specific factors that are associated with asthma among U.S. adults.

\section{Methods}

Behavioral Risk Factors Surveillance System (BRFSS) Data BRFSS county-level data for the years 2007 to 2012 was downloaded from the BRFSS website (http://www.cdc.gov/ brfss/). For our primary analysis, we combined the 6 years of survey data. Respondents were classified as having asthma based on affirmative answers to both of the BRFSS questions 1) "Have you ever been told by a doctor, nurse, or other health professional that you had asthma?" and 2) "Do you still have asthma?" The never asthma group consisted of respondents who answered "no" to the first question. We used the following individual response variables to capture information about respondent demographics and socioeconomic factors: age, gender, race/ethnicity, education level, household income, body mass index (BMI), and smoking status. Race/ethnicity included respondents classified as White, Black, American Indian/Alaskan Native, Asian/Pacific Islander, and Hispanic. Education level was re-leveled into three categories: less than high school, high school, some college or more. Household yearly income was re-leveled into three categories: $<\$ 25,000 ; \$ 25,000$ $\$ 75,000 ; \geq \$ 75,000$. Smoking status was re-leveled into three groups: current smoker, former smoker, and never smoker. BMI was re-leveled into five groups: not overweight or obese $\left(<25.0 \mathrm{~kg} / \mathrm{m}^{2}\right)$, overweight $\left(25.0\right.$ to $\left.<30.0 \mathrm{~kg} / \mathrm{m}^{2}\right)$, grade 1 obese $\left(30.0\right.$ to $\left.<35.0 \mathrm{~kg} / \mathrm{m}^{2}\right)$, grade 2 obese $\left(35.0 \mathrm{~kg} / \mathrm{m}^{2}\right.$ to $<$ $\left.40.0 \mathrm{~kg} / \mathrm{m}^{2}\right)$ and grade 3 obese $\left(\geq 40.0 \mathrm{~kg} / \mathrm{m}^{2}\right)$. Respondents who were less than 22 years of age were excluded to reduce bias in response to education level and yearly household income questions from those who would not have begun college or working due to young age.

\section{National Health and Nutrition Examination Survey (NHANES) Data}

NHANES data for the years 2007-2008, 2009-2010, and 2011-2012 was obtained using the nhanesA R package (https://CRAN.R-project.org/package=nhanesA). Respondents were classified as having asthma based on affirmative answers to both of the NHANES questions 1) "Has a doctor or other health professional ever told you that you have asthma?" and 2) "Do you still have asthma?" The never asthma group consisted of respondents who answered "no" to the first question. We used the following individual response variables to capture similar information about respondents as was captured with BRFSS: age, gender, race/ethnicity, education level, poverty-to-income ratio (PIR), BMI, and smoking status. Race/ethnicity included respondents in all NHANES categories, though Mexican was integrated into Other Hispanic to be consistent with the BRFSS categories: NonHispanic White, Non-Hispanic Black, Hispanic, and Other. PIR was re-leveled into two categories: income below poverty line: $\leq 1$, income above poverty line: $>1$. Education level, smoking status and BMI were re-leveled into the same groups that were used with BRFSS. Respondents who were less than 22 years of age were excluded from analysis.

\section{Statistical analysis}

Statistical analyses were conducted in $\mathrm{R}$ [32]. To determine factors associated with asthma, we used logistic 
regression analyses. Crude odds ratios (ORs) were computed with complete cases for each variable individually. To determine gender-specific factors associated with asthma, adjusted ORs were computed with all potential risk factors included in separate models for female and male respondents. To obtain estimates that were generalizable to the U.S. population, weighted analyses were conducted using the $\mathrm{R}$ survey package with CDC-computed study-specific weights provided for each respondent. Collinearity was assessed by estimating variance inflation factors with the $\mathrm{R}$ car package.

\section{Results}

We obtained BRFSS data for 1,316,013 respondents at least 22 years of age from datasets corresponding to years 2007-2012. Subjects who responded "yes" to the question "Have you ever been told by a doctor, nurse, or other health professional that you had asthma?" but "no" to "Do you still have asthma?" were excluded from analyses. Missing rates for most variables was low $(<5 \%)$, except for yearly household income, which was missing in $13.14 \%$ of respondents [Table 1]. Subjects included in the study vs. subjects excluded due to missing data had statistically significant differences in all categories $(p<0.0001)$, however, the ratios for asthma, race/ethnicity, and smoking status levels were similar. Variables that were most differently distributed between study and excluded subjects were gender $(59 \%$ females included vs. $71 \%$ excluded), education level (68\% included vs. $59 \%$ excluded had some college or more), yearly household income (32\% included vs. $26 \%$ excluded had $\geq \$ 75,000$ ), BMI (36\% included vs. $41 \%$ excluded were not overweight or obese), and age ( $29 \%$ included vs. $40 \%$ excluded were 65 + years old). We restricted further analyses to the $1,003,894$ respondents with complete data.

The weighted asthma prevalence for all respondents, who resided in 408 U.S. counties, was $8.41 \%$ [Fig. 1]. Asthma prevalence did not change greatly or monotonically over the 6 -year span, ranging between $7.94 \%$ and 8.85\% [see Table E1 in the Online Repository]. The demographic characteristics of respondents with asthma differed from those of never asthma respondents [Table 2]. From univariate analyses, asthma prevalence was increased in respondents who were female, obese, current or past smokers compared to never smokers, and had low yearly household income. Additionally, black and American Indian/Alaskan Native respondents had higher asthma prevalence relative to white respondents, while Asian/Pacific Islander and Hispanic respondents had lower asthma prevalence relative to white respondents. The percentages of respondents within categories in Table 2 and the crude ORs in Table 3 provide quantitative results illustrating such differences. Most notably, the grade 2 obese and grade 3 obese categories of BMI were strongly associated with asthma vs. not overweight or obese (crude OR 2.11; 95\% CI: 2.00-2.23 and 3.30; 95\% CI: 3.11-3.50, respectively); female vs. male gender had asthma crude OR 1.80 (95\% CI: 1.74$1.86)$; and $<\$ 25,000$ vs. $>\$ 75,000$ yearly household income had asthma crude OR 1.60 (95\% CI: 1.54-1.66).

Due to the high crude OR of female compared to male gender, and the possible interaction of gender with other demographic and socioeconomic variables, we performed adjusted analyses for males and females separately to determine which factors were independently associated with asthma in a gender-specific fashion [Table 4]. Weighted asthma prevalence in males was $6.20 \%$ and in females was $10.62 \%$. Asthma prevalence rates did not change greatly or monotonically over the 6-year span for either gender: the range was $5.69 \%-6.54 \%$ in males and $10.17 \%-11.22 \%$ in females [See Additional file 1: Tables E2 and E3 in the Online Repository]. We did not observe multi-collinearity between independent variables (all had generalized variance inflation factors $<2$ ), suggesting that inclusion of all terms in regression models was appropriate.

In adjusted analyses, the effects of BMI and smoking status differed by gender [Table 4]. The adjusted ORs for asthma increased with increasing BMI more steeply in women than men. While grade 2 obese and grade 3 obese male respondents had a 1.69 and 2.35 times increased prevalence of asthma vs. not overweight or obese males (95\% CI: $1.52-1.87$ and 2.07-2.68), grade 2 obese and grade 3 obese female respondents had a 2.48 and 3.49 times increased prevalence of asthma vs. not overweight or obese females (95\% CI: 2.33-2.64 and 3.26-3.73); grade 1 obese males had a 1.22 times increased prevalence compared to not overweight or obese males (95\% CI: 1.13-1.33) and grade 1 obese females had a 1.82 times increased prevalence compared to not overweight or obese females (95\% CI: 1.73-1.91); overweight females had a 1.35 times increased asthma prevalence compared to their not overweight or obese counterparts (95\% CI: 1.291.40), but overweight males did not have a significantly increased prevalence compared to their not overweight or obese counterparts. Females that were current smokers had a 1.41 times increased asthma prevalence compared to females that never smoked (95\% CI: 1.34-1.47), and males that were current smokers had a 1.11 times increased prevalence compared to males that never smoked (95\% CI: 1.03-1.20); female former smokers had a 1.27 times increased prevalence compared to their counterparts who never smoked (95\% CI: 1.23-1.32), while male former smokers had a 1.16 times increased prevalence compared to their counterparts who never smoked (95\% CI: 1.09-1.23).

The effects of race/ethnicity, education, yearly household income, and age varied less by gender in adjusted 
Table 1 BRFSS Respondent Characteristics. Overall characteristics of complete cases used in analyses (i.e., Study Subjects) and those excluded due to missing data (i.e., Incomplete Cases) corresponding to BRFSS surveys from years 2007-2012. For each category, N (\%) for raw data are shown

\begin{tabular}{|c|c|c|c|}
\hline & $\begin{array}{l}\text { Missing } \\
\text { Responses }\end{array}$ & $\begin{array}{l}\text { Study Subjects } \\
(N=1,003,894)\end{array}$ & $\begin{array}{l}\text { Incomplete Cases } \\
(N=258,370)\end{array}$ \\
\hline Asthma & $4,885(0.39)$ & & \\
\hline No Asthma & & $910,446(90.69)$ & $228,298(90.06)$ \\
\hline Asthma & & $93,448(9.31)$ & $25,187(9.94)$ \\
\hline Gender & $0(0.00)$ & & \\
\hline Male & & $408,785(40.72)$ & $74,797(28.95)$ \\
\hline Female & & $595,109(59.28)$ & $183,573(71.05)$ \\
\hline Race/Ethnicity & $49,411(3.91)$ & & \\
\hline White & & $791,219(78.81)$ & $161,124(77.11)$ \\
\hline Black & & $94,962(9.46)$ & $20,136(9.64)$ \\
\hline American Indian/Alaskan Native & & $8,995(0.90)$ & $1,910(0.91)$ \\
\hline Asian/Pacific Islander & & $31,782(3.17)$ & $6,226(2.98)$ \\
\hline Hispanic & & $76,936(7.66)$ & $19,563(9.36)$ \\
\hline Education level & $5,079(0.40)$ & & \\
\hline Less than high school & & $22,554(2.25)$ & $12,388(4.89)$ \\
\hline High school & & $300,157(29.90)$ & $90,843(35.87)$ \\
\hline Some college or more & & $681,183(67.85)$ & $150,060(59.24)$ \\
\hline Yearly Household income (USD) & $165,884(13.14)$ & & \\
\hline$<\$ 25,000$ & & $253,845(25.29)$ & $30,061(32.50)$ \\
\hline$\$ 25,000-\$ 75,000$ & & $424,416(42.28)$ & $38,185(41.29)$ \\
\hline$\geq \$ 75,000$ & & $325,633(32.44)$ & $24,240(26.21)$ \\
\hline Body Mass Index (BMI) & $63,813(5.06)$ & & \\
\hline Not overweight or obese & & $364,981(36.36)$ & $79,819(41.03)$ \\
\hline Overweight & & $370,007(36.86)$ & $68,578(35.25)$ \\
\hline Grade 1 obese & & 170,604 (16.99) & $29,649(15.24)$ \\
\hline Grade 2 obese & & $61,508(6.13)$ & $10,193(5.24)$ \\
\hline Grade 3 obese & & $36,794(3.67)$ & 6,318 (3.25) \\
\hline Smoking status & $10,969(0.87)$ & & \\
\hline Never smoked & & $533,717(53.16)$ & $139,077(56.22)$ \\
\hline Former smoker & & 310,507 (30.93) & 73,486 (29.70) \\
\hline Current smoker & & $159,670(15.91)$ & $34,838(14.08)$ \\
\hline Age & $13,785(1.09)$ & & \\
\hline $22-34$ & & 118,250 (11.78) & $28,139(11.50)$ \\
\hline $35-44$ & & $159,672(15.91)$ & $29,622(12.11)$ \\
\hline $45-54$ & & $211,528(21.07)$ & 41,017 (16.77) \\
\hline $55-64$ & & $225,722(22.48)$ & 48,606 (19.87) \\
\hline $65+$ & & $288,722(28.76)$ & 97,201 (39.74) \\
\hline
\end{tabular}

analyses. Black race/ethnicity relative to white did not have a significant effect on asthma prevalence in males, but had a 0.93 times decreased prevalence in females (95\% CI: 0.89-0.98); American Indian/Alaskan Native race/ethnicity had an increased prevalence in both genders: 1.36 times in males (95\% CI: 1.00-1.86) and 1.47 times in females (95\% CI: 1.28-1.70). Asian/Pacific Islander race/ethnicity had a decreased prevalence in both genders: 0.72 times in males (95\% CI: 0.61-0.85) and 0.62 times in females (95\% CI: 0.54-0.71); Hispanic race/ ethnicity also had a decreased prevalence in both genders: 0.56 times in males (95\% CI: 0.50-0.62) and 0.72 


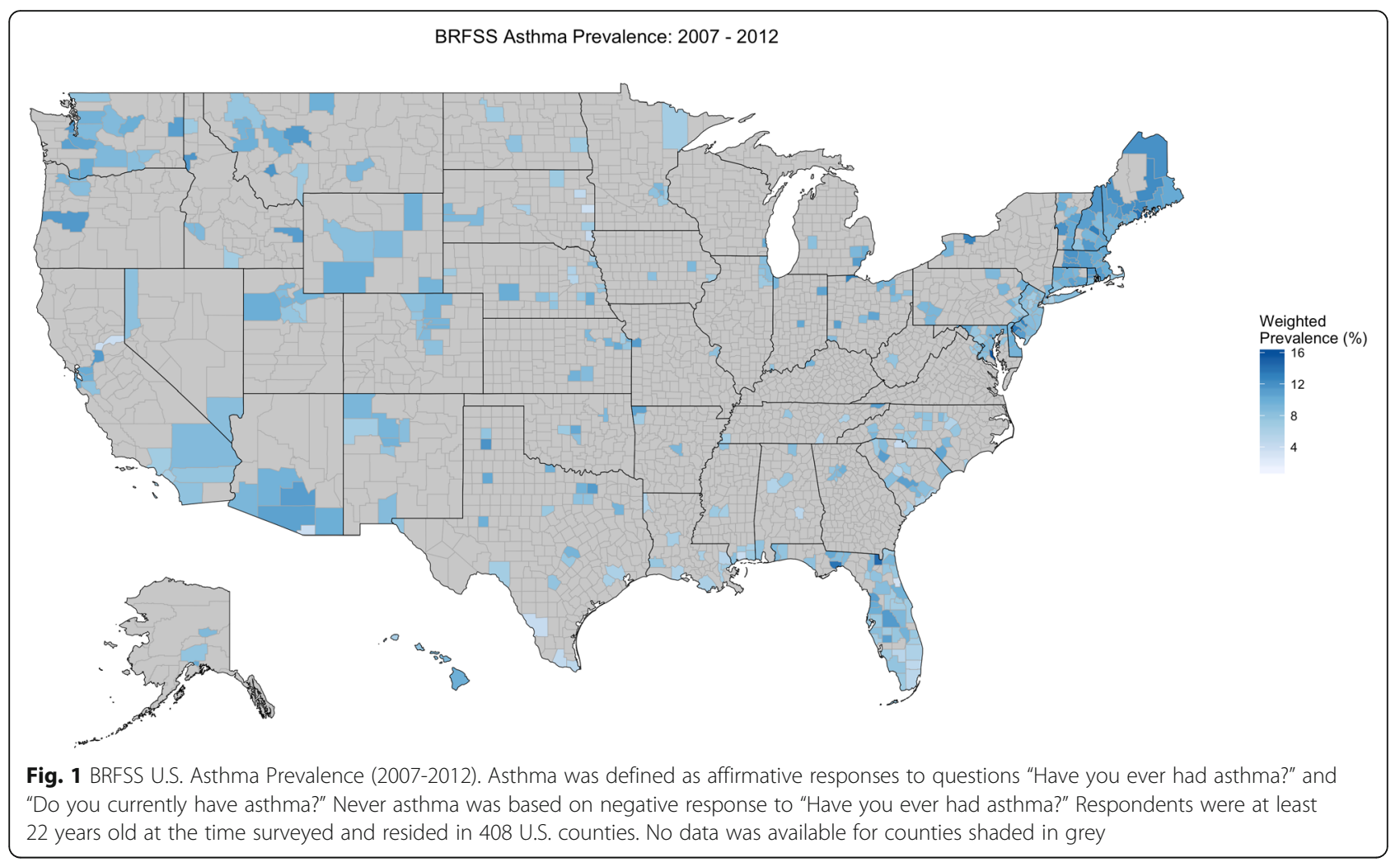

times in females (95\% CI: 0.67-0.77). Less than high school education level was associated with a decreased asthma prevalence of 0.76 times in males (95\% CI: 0.63$0.93)$ and 0.66 times in females (95\% CI: 0.58-0.74) relative to some college or more. $<\$ 25,000$ yearly household income was associated with a 1.61 times increased asthma prevalence in males (95\% CI: 1.49-1.74) and a 1.53 times increased asthma prevalence in females $(95 \%$ CI: $1.45-1.60)$ relative to $\geq \$ 75,000$ yearly household income.

Results obtained for males and females for each of the six BRFSS yearly datasets showed consistency across individual years for association of factors with asthma [See Additional file 1: Tables E2 and E3 in the Online Repository]. The ORs of American Indian/Alaskan Native race/ethnicity category were the most variable across years, consistent with this category having fewer respondents than others, and hence, greater uncertainty in values reported. County-level characteristics based on complete cases used in the analysis are available at http://asthmamaps.org.

Similar results to those obtained with BRFSS data were obtained with NHANES. Overall weighted asthma prevalence for 2007-2012 was $8.22 \%$ according to NHANES vs. 8.41\% according to BRFSS. Asthma prevalence was $6.23 \%$ for men and $10.02 \%$ for women according to NHANES, vs. $6.20 \%$ for men and $10.62 \%$ for women according to BRFSS. In adjusted analyses, the effects of BMI and smoking status also differed by gender in NHANES, and the adjusted ORs for asthma increased with increasing BMI more steeply in women than men [Table 5]. Grade 2 obese and grade 3 obese male respondents did not have a significant increased prevalence of asthma vs. their not overweight or obese counterparts, while grades 2 and grade 3 obese female respondents had a 2.00 and 3.30 times increased prevalence of asthma vs. not overweight or obese females (95\% CI: 1.47-2.72 and 95\% CI: 2.19-4.97). Females that were current smokers had a 1.78 times increased asthma prevalence compared to females that never smoked (95\% CI: 1.35-2.33), and males that were current smokers did not have a statistically significant difference in asthma prevalence compared to males that never smoked. The effects of race/ethnicity, education, PIR, and age varied less by gender.

\section{Discussion}

Using 2007-2012 BRFSS data from 1,003,894 U.S. adult respondents, we quantified the association between asthma and socioeconomic and demographic factors. The strongest non-modifiable factor associated with asthma was gender, with women having an OR of 1.80 (95\% CI 1.74-1.86) relative to men. We next performed gender-stratified BRFSS adjusted analyses to identify independent risk factors that varied in men and women. Similar analyses with NHANES adult data from 20072012 were performed to confirm BRFSS findings. While 
Table 2 Asthma Prevalence by Demographic Categories. Overall characteristics of 2007-2012 BRFSS respondents according to asthma status. Counts provided (N) are for raw data. Weighted \% are percentages obtained from analyzing BRFSS data using survey design with CDC-provided individual respondent weights, and thus, do not correspond directly to the raw counts. The weighted prevalence of asthma was $8.41 \%$

\begin{tabular}{|c|c|c|c|c|}
\hline & \multicolumn{2}{|l|}{ Asthma } & \multicolumn{2}{|c|}{ Never Asthma } \\
\hline & \multicolumn{2}{|c|}{$(N=93,448)$} & \multicolumn{2}{|c|}{$(N=910,446)$} \\
\hline & $\mathrm{N}$ & Weighted \% & $\mathrm{N}$ & Weighted \% \\
\hline \multicolumn{5}{|l|}{ Gender } \\
\hline Male & 26,490 & 36.8 & 382,295 & 51.1 \\
\hline Female & 66,958 & 63.2 & 528,151 & 48.9 \\
\hline \multicolumn{5}{|l|}{ Race/Ethnicity } \\
\hline White & 72,488 & 69.1 & 718,731 & 66.3 \\
\hline Black & 10,643 & 14.4 & 84,319 & 11.7 \\
\hline American Indian/Alaskan Native & 1,238 & 1.2 & 7,757 & 0.7 \\
\hline Asian/Pacific Islander & 2,083 & 3.3 & 29,699 & 5.4 \\
\hline Hispanic & 6,996 & 12.0 & 69,940 & 15.9 \\
\hline \multicolumn{5}{|l|}{ Education Level } \\
\hline Less than high school & 2,584 & 3.0 & 19,970 & 4.0 \\
\hline High school & 30,212 & 30.8 & 269,945 & 29.1 \\
\hline Some college or more & 60,652 & 66.2 & 620,531 & 66.9 \\
\hline \multicolumn{5}{|l|}{ Yearly Household Income (USD) } \\
\hline$<\$ 25,000$ & 33,218 & 31.5 & 220,627 & 23.5 \\
\hline$\$ 25,000-\$ 75,000$ & 36,290 & 37.6 & 388,126 & 39.6 \\
\hline$\geq \$ 75,000$ & 23,940 & 30.9 & 301,693 & 36.9 \\
\hline \multicolumn{5}{|l|}{ Body Mass Index (BMI) } \\
\hline Not overweight or obese & 26,807 & 29.7 & 338,174 & 36.7 \\
\hline Overweight & 29,952 & 32.8 & 340,055 & 37.8 \\
\hline Grade 1 obese & 18,945 & 19.7 & 151,659 & 16.8 \\
\hline Grade 2 obese & 9,535 & 9.7 & 51,973 & 5.6 \\
\hline Grade 3 obese & 8,209 & 8.1 & 28,585 & 3.0 \\
\hline \multicolumn{5}{|l|}{ Smoking Status } \\
\hline Never smoked & 45,124 & 52.5 & 488,593 & 57.6 \\
\hline Former smoker & 30,494 & 27.5 & 280,013 & 25.8 \\
\hline Current smoker & 17,830 & 20.0 & 141,840 & 16.6 \\
\hline \multicolumn{5}{|l|}{ Age } \\
\hline $22-34$ & 11,824 & 25.8 & 106,426 & 24.5 \\
\hline $35-44$ & 14,857 & 20.8 & 144,815 & 22.2 \\
\hline $45-54$ & 20,414 & 21.2 & 191,114 & 21.2 \\
\hline $55-64$ & 22,190 & 16.7 & 203,532 & 15.7 \\
\hline $65+$ & 24,163 & 15.5 & 264,559 & 16.5 \\
\hline
\end{tabular}

NHANES was a much smaller study $(n=13,364)$, some of its data is considered more reliable than that of BRFSS, as interviews were performed in-person and measures such as height and weight were obtained during physical exams, rather than via phone interviews.

The strongest association observed for asthma in both BRFSS and NHANES was with obesity, and this risk factor was particularly important among women. Our findings are consistent with the growing body of literature on the relationship between obesity and asthma, and more generally, metabolic syndrome and lung disease [33-36]. Prospective studies have found a doseresponse relationship between the odds of asthma incidents and being overweight or obese [37, 38], and data 
Table 3 Factors Associated with Asthma Prevalence in BRFSS Univariate Analyses. Crude odds ratios (ORs) were derived from unadjusted survey logistic regression models with asthma as the outcome. Shown are ORs and 95\% confidence intervals (Cls)

\begin{tabular}{|c|c|}
\hline & $\begin{array}{l}\text { Crude ORs } \\
(N=1,003,894)\end{array}$ \\
\hline \multicolumn{2}{|l|}{ Gender } \\
\hline Male & Reference \\
\hline Female & $1.80(1.74,1.86)^{* *}$ \\
\hline \multicolumn{2}{|l|}{ Race/Ethnicity } \\
\hline White & Reference \\
\hline Black & $1.18(1.13,1.23)^{* *}$ \\
\hline American Indian/Alaskan Native & $1.64(1.42,1.90)^{* *}$ \\
\hline Asian/Pacific Islander & $0.59(0.53,0.65)^{* *}$ \\
\hline Hispanic & $0.72(0.69,0.76)^{* *}$ \\
\hline \multicolumn{2}{|l|}{ Education level } \\
\hline Less than high school & $0.76(0.69,0.84)^{* *}$ \\
\hline High school & $1.07(1.04,1.10)^{* *}$ \\
\hline Some college or more & Reference \\
\hline \multicolumn{2}{|l|}{ Yearly Household income (USD) } \\
\hline$<\$ 25,000$ & $1.60(1.54,1.66)^{* *}$ \\
\hline$\$ 25,000-\$ 75,000$ & $1.14(1.10,1.18)^{* *}$ \\
\hline$\geq \$ 75,000$ & Reference \\
\hline \multicolumn{2}{|l|}{ Body Mass Index (BMI) } \\
\hline Not overweight or obese & Reference \\
\hline Overweight & $1.07(1.03,1.11)^{* *}$ \\
\hline Grade 1 obese & $1.45(1.39,1.51)^{* *}$ \\
\hline Grade 2 obese & $2.11(2.00,2.23)^{* *}$ \\
\hline Grade 3 obese & $3.30(3.11,3.50)^{* *}$ \\
\hline \multicolumn{2}{|l|}{ Smoking status } \\
\hline Never smoked & Reference \\
\hline Former smoker & $1.17(1.13,1.20)^{* *}$ \\
\hline Current smoker & $1.32(1.27,1.37)^{* *}$ \\
\hline \multicolumn{2}{|l|}{ Age } \\
\hline 10 years & $0.98(0.97,0.99)^{* *}$ \\
\hline
\end{tabular}

from animal and human studies have shown that increases of normal adipose tissue lead to a systemic proinflammatory state [39]. Although the precise mechanism by which obesity contributes to asthma is not known, based on our findings and those of others, decreasing obesity should be a primary goal of interventions intended to reduce asthma. Our finding that obesity is a strong risk factor for asthma particularly in women is also consistent with a recent report based on U.S. National Health and Nutrition Examination Survey data, although in contrast with our results, that report found that obesity was not a significant risk factor in men [40]. The reason why obese women are at greater risk for asthma than obese men is not known.
Table 4 Gender-Specific Factors Associated with Asthma Prevalence in BRFSS Multivariate Analyses. Adjusted odds ratios (ORs) were derived separately for males and females from adjusted survey logistic regression models with asthma as the outcome. Shown are ORs and 95\% confidence intervals (Cls)

\begin{tabular}{|c|c|c|}
\hline & $\begin{array}{l}\text { Male Adjusted ORs } \\
(N=408,785)\end{array}$ & $\begin{array}{l}\text { Female Adjusted ORs } \\
(N=595,109)\end{array}$ \\
\hline Weighted Asthma Prevalence (\%) & 6.20 & 10.62 \\
\hline \multicolumn{3}{|l|}{ Race/Ethnicity } \\
\hline White & Reference & Reference \\
\hline Black & $0.97(0.89,1.06)$ & $0.93(0.89,0.98)^{*}$ \\
\hline American Indian/Alaskan Native & $1.36(1.00,1.86)$ & $1.47(1.28,1.70)^{* *}$ \\
\hline Asian/Pacific Islander & $0.72(0.61,0.85)^{* *}$ & $0.62(0.54,0.71)^{* *}$ \\
\hline Hispanic & $0.56(0.50,0.62)^{* *}$ & $0.72(0.67,0.77)^{* *}$ \\
\hline \multicolumn{3}{|l|}{ Education level } \\
\hline Less than high school & $0.76(0.63,0.93)^{*}$ & $0.66(0.58,0.74)^{* *}$ \\
\hline High school & $0.91(0.85,0.97)^{*}$ & $0.87(0.83,0.90)^{* *}$ \\
\hline Some college or more & Reference & Reference \\
\hline \multicolumn{3}{|l|}{ Yearly Household income (USD) } \\
\hline$<\$ 25,000$ & $1.61(1.49,1.74)^{* *}$ & $1.53(1.45,1.60)^{* *}$ \\
\hline$\$ 25,000-\$ 75,000$ & $1.09(1.02,1.15)^{*}$ & $1.07(1.03,1.12)^{* *}$ \\
\hline$\geq \$ 75,000$ & Reference & Reference \\
\hline \multicolumn{3}{|l|}{ Body Mass Index (BMI) } \\
\hline Not overweight or obese & Reference & Reference \\
\hline Overweight & $1.01(0.94,1.08)$ & $1.35(1.29,1.40)^{* *}$ \\
\hline Grade 1 obese & $1.22(1.13,1.33)^{* *}$ & $1.82(1.73,1.91)^{* *}$ \\
\hline Grade 2 obese & $1.69(1.52,1.87)^{* *}$ & $2.48(2.33,2.64)^{* *}$ \\
\hline Grade 3 obese & $2.35(2.07,2.68)^{* *}$ & $3.49(3.26,3.73)^{* *}$ \\
\hline \multicolumn{3}{|l|}{ Smoking status } \\
\hline Never smoked & Reference & Reference \\
\hline Former smoker & $1.16(1.09,1.23)^{* *}$ & $1.27(1.23,1.32)^{* *}$ \\
\hline Current smoker & $1.11(1.03,1.20)^{*}$ & $1.41(1.34,1.47)^{* *}$ \\
\hline \multicolumn{3}{|l|}{ Age } \\
\hline 10 Years & $0.94(0.93,0.96)^{* *}$ & $0.95(0.94,0.97)^{* *}$ \\
\hline
\end{tabular}

Current smoking was another modifiable factor that was associated with asthma and had a greater effect in women than in men. The association between smoking and increased risk of asthma is well-documented, but there is little functional evidence that directly links smoking to asthma and it is unclear why the association is more pronounced in women than men [41, 42]. The genderspecific disparity observed between women and men was larger in NHANES than in BRFSS: women who were current smokers in NHANES had an OR of 1.78 for having asthma vs. never smokers, while those in BRFSS had an OR of 1.41. We are unable to determine whether this 
Table 5 Gender-Specific Factors Associated with Asthma Prevalence in NHANES Multivariate Analyses. Adjusted odds ratios (ORs) were derived separately for males and females from adjusted survey logistic regression models with asthma as the outcome. Shown are ORs and 95\% confidence intervals (Cls)

\begin{tabular}{|c|c|c|}
\hline & $\begin{array}{l}\text { Male Adjusted ORs } \\
(N=6,476)\end{array}$ & $\begin{array}{l}\text { Female Adjusted ORs } \\
(N=6,888)\end{array}$ \\
\hline Weighted Asthma Prevalence (\%) & 6.23 & 10.02 \\
\hline \multicolumn{3}{|l|}{ Race/Ethnicity } \\
\hline White & Reference & Reference \\
\hline Black & $0.98(0.73,1.33)$ & $0.95(0.76,1.18)$ \\
\hline Hispanic & $0.39(0.26,0.59)^{* *}$ & $0.62(0.46,0.83)^{*}$ \\
\hline Other & $0.80(0.48,1.35)$ & $0.77(0.49,1.21)$ \\
\hline \multicolumn{3}{|l|}{ Education level } \\
\hline Less than high school & $1.04(0.76,1.42)$ & $0.86(0.68,1.10)$ \\
\hline High school & $0.81(0.54,1.23)$ & $0.91(0.70,1.19)$ \\
\hline Some college or more & Reference & Reference \\
\hline \multicolumn{3}{|l|}{ Poverty income ratio } \\
\hline$\leq 1$ & $1.70(1.24,2.34)^{*}$ & $1.78(1.44,2.20)^{* *}$ \\
\hline$>1$ & Reference & Reference \\
\hline \multicolumn{3}{|l|}{ Body Mass Index (BMI) } \\
\hline Not overweight or obese & Reference & Reference \\
\hline Overweight & $0.91(0.64,1.29)$ & $1.39(1.06,1.81)^{*}$ \\
\hline Grade 1 obese & $1.18(0.85,1.63)$ & $1.97(1.54,2.52)^{* *}$ \\
\hline Grade 2 obese & $1.69(0.99,2.89)$ & $2.00(1.47,2.72)^{* *}$ \\
\hline Grade 3 obese & $1.74(0.87,3.48)$ & $3.30(2.19,4.97)^{* *}$ \\
\hline \multicolumn{3}{|l|}{ Smoking status } \\
\hline Never smoked & Reference & Reference \\
\hline Former smoker & $1.34(0.96,1.87)$ & $1.28(1.00,1.63)$ \\
\hline Current smoker & $1.27(0.86,1.89)$ & $1.78(1.35,2.33)^{* *}$ \\
\hline \multicolumn{3}{|l|}{ Age } \\
\hline 10 Years & $1.03(0.94,1.12)$ & $0.97(0.90,1.04)$ \\
\hline
\end{tabular}

difference is due to unequal response reliability between the two studies or a reflection of cohort size differences.

While previous studies suggest that individuals differ in their genetic predisposition to asthma owing to differences in genetic ancestry that are reflected in racial/ethnic categories [8-10,43], our BRFSS results suggest that other factors, such as income, more prominently lead to disparities in asthma prevalence by race/ethnicity. Although black and American Indians/Alaskan Native respondents had increased odds of asthma relative to white respondents in unadjusted analyses, after adjusting for other factors and stratifying by gender, the association with black race/ethnicity was not significant in males and led to decreased odds of asthma in females, and the association with American Indians/Alaskan Natives was considerably decreased in magnitude in both men and women. In NHANES adjusted analyses, statistically significant differences in asthma prevalence were observed for Hispanic men and women, who had the lowest prevalence of asthma among racial/ethnic groups.

The categorization of Hispanic respondents is limited, especially for BRFSS, in that we do not know respondent country of origin and large differences in asthma rates are known to occur among such groups: Mexican Americans have the lowest rate of asthma in the U.S. while Puerto Rican Americans have the highest rate [7]. Because BRFSS attempts to represent the U.S. population, the Hispanic results from this study most likely reflect responses from Mexican Americans, who according to the 2010 US census represent $63 \%$ of Hispanics in the U.S. Puerto Ricans, who are the next largest group, represent $9.2 \%$ of U.S. Hispanics [44]. NHANES included a Mexican American racial/ethnic category, and respondents who were classified in this group did have lowest asthma rates consistent with previous findings [7]: NHANES Mexican American males and females had adjusted ORs for asthma of 0.28 (95\% CI: 0.17-0.45) and 0.35 (95\% CI: 0.24-0.52), respectively, while NHANES Other Hispanic males and females had adjusted ORs for asthma of 0.59 (95\% CI: 0.36-0.95) and 0.97 (95\% CI: 0.71-1.32), respectively. Studies that gather more detailed information regarding Hispanic country of origin are likely to be more informative regarding the influence of demographic and socio-economic factors and asthma among U.S. Hispanics.

In BRFSS, low yearly household income $(<\$ 25,000)$ remained a significant risk factor for asthma in both genders after adjusting for other socioeconomic and demographic factors. Because a greater proportion of black and American Indian/Alaskan Native relative to white BRFSS respondents had low income, unadjusted analyses found stronger race/ethnicity associations within these groups. Our NHANES results also found that individuals of both genders living below the poverty line (PIR $\leq 1$ ) were at increased risk of having asthma. The association between poverty and asthma has been observed and explored for many years [43, 45-47], and our results support the notion that individuals living in poverty experience a higher disease burden of asthma in the U.S. Continued studies that seek to understand the environmental and healthcare access factors, including geneenvironment interactions [48], exposures (e.g., mold, cockroaches, and house dust mites) $[49,50]$ and health literacy $[12,51]$, that are associated with low income status and disproportionately affect some minority groups will decrease in asthma prevalence disparities by race/ethnicity.

Our findings are consistent with previous studies that used smaller portions of BRFSS data to examine demographic factors associated with asthma, although none 
performed gender-specific analyses [23, 24]. A study that used 2000 BRFSS data also found that obesity, female gender, current/past smoking, and low socioeconomic status were associated with asthma [24]. Another study that used 2009-2010 BRFSS data and performed race/ ethnicity stratified analyses found that asthma risk factors differed by race/ethnicity [23]. For example, female gender and low income status were associated with asthma in all groups other than Asian/Pacific Islanders, and obesity was associated with asthma in all groups other than American Indians/Alaskan Natives [23].

By using NHANES and BRFSS data while accounting for their survey design, we obtained nationally representative measures from two independent studies with a large number of diverse participants. Although results from both studies were highly consistent, both datasets are subject to limitations. We were unable to make inferences about causality of observed associations due to the cross-sectional nature of BRFSS and NHANES. While the reliability and validity of BRFSS is high [17, 18], a study comparing it to other national surveys found that BRFSS asthma prevalence estimates were higher than those of the National Health Interview Survey (NHIS) [52]. BRFSS relies solely on self-reported data, and is thus, subject to error. Further, while we used a weighted survey design, residual bias from differences between survey respondents and the U.S. adult population may still affect our results. For example, BRFSS respondents were $60 \%$ female and $40 \%$ male, a distribution that is very skewed compared to the U.S. population. Comparison of other characteristics of our BRFSS respondents to those of the general U.S. population reveal other differences: (1) our study subjects consisted of 79\% non-Hispanic White, 9\% nonHispanic Black, 8\% Hispanic, 3\% Asian/Pacific Islander and $1 \%$ American Indian/Alaskan Native respondents, while the 2010 U.S. Census reported a population of $64 \%$ non-Hispanic White, 13\% Black, 16\% Hispanic, 5\% Asian/Pacific Islander and 1\% American Indian/Alaskan Native [53], (2) $98 \%$ of our study subjects (all at least 22 years old) completed high school or more and $68 \%$ completed some college or more, while according to the American Community Survey, in $2015,88 \%$ of the U.S. population at least 25 years old completed high school or higher and $59 \%$ had completed some college or more [54]. Household income of our study subjects was consistent with the U.S. mean of $\$ 55,775$ in 2015 according to the American Community Survey [55], as 25\% of our study subjects had a household income below $\$ 25,000,42 \%$ had a household income between $\$ 25,000$ and $\$ 75,000$, and $32 \%$ had a household income above $\$ 75,000$. The consistency we observed for BMI association results between BRFSS and NHANES suggests that self-reported measures of BMI from BRFSS were as reliable as those for NHANES, or that owing to its larger sample size, bias errors from BRFSS did not affect overall results for at least this variable. We used complete cases for our study, which may have introduced bias related to questions not answered by some groups although our sample size was large and included many subjects in most categories.

\section{Conclusions}

Our results underscore the importance of obesity and smoking as asthma risk factors among US adults that impact women more strongly than men. To reduce asthma prevalence in adults overall, studies should continue to focus on identifying functional mechanisms by which women disproportionately develop asthma, as well as design interventions that effectively reduce obesity and smoking.

\section{Additional file}

Additional file 1: This file contains three tables that provide yearly results of BRFSS data for 2007-2012. Table E1 contains results for all subjects. Tables E2 and E3 provide results for Male and Female subjects, respectively. (DOCX $161 \mathrm{~kb}$ )

\section{Abbreviations}

BMI: Body mass index; BRFSS: Behavioral risk factors surveillance system; CDC: Centers for disease control \& prevention; Cl: confidence interval; FIPS: Federal Information Processing Standard; NHANES: National Health and Nutrition Examination Survey; OR: Odds ratio

\section{Acknowledgements}

We would like to thank Tara Jackson and Krista Heinlen from the University of Pennsylvania Cartographic Modeling Lab for downloading and preformatting the BRFSS data used for this project.

\section{Funding}

Funding was provided by National Institutes of Health (NIH) R00 HL105663.

Availability of data and materials

BRFSS data is available at http://www.cdc.gov/brfss/. NHANES data is available at http://www.cdc.gov/nchs/nhanes/.

\section{Authors' contributions}

RG, OM, EZ, BEH performed analysis. MR provided statistical analysis guidance. BEH designed the study. RG, OM, EZ, MR, BEH wrote the manuscript. All authors read and approved the final manuscript.

\section{Competing interests}

The funders had no role in study design, data collection and analysis, decision to publish, or preparation of the manuscript. The authors declare that they have no competing interests.

Consent for publication

Not applicable.

\section{Ethics approval and consent to participate}

The BRFSS was approved by the Institutional Review Board of each participating U.S. state or territory health department. The NHANES was approved by the Institutional Review Board of the National Center for Health Statistics of the CDC. Informed consent was obtained from all participants. 


\section{Author details}

1 Department of Biostatistics and Epidemiology, University of Pennsylvania, 219 Blockley Hall, 423 Guardian Drive, Philadelphia, PA 19104, USA. ${ }^{2}$ Bloomberg School of Public Health, Johns Hopkins University, Baltimore, MD 21218, USA.

Received: 3 November 2016 Accepted: 5 January 2017

Published online: 24 January 2017

\section{References}

1. Akinbami L, Moorman J, Bailey C, Zahran H, King M, Johnson C, Liu X. Trends in asthma prevalence, health care use, and mortality in the United States, 2001-2010. In: NCHS data brief, no 94. Hyattsville: National Center for Health Statistics; 2012.

2. Schiller JS, Lucas JW, Ward BW, Peregoy JA. Summary health statistics for U. S. adults: National Health Interview Survey, 2010. Vital and health statistics Series 10, Data from the National Health Survey. 2012;252:1-207.

3. Bonds RS, Midoro-Horiuti T. Estrogen effects in allergy and asthma. Curr Opin Allergy Clin Immunol. 2013;13:92-9.

4. Britton J, Pavord I, Richards K, Knox A, Wisniewski A, Wahedna I, Kinnear W, Tattersfield A, Weiss S. Factors influencing the occurrence of airway hyperreactivity in the general population: the importance of atopy and airway calibre. Eur Respir J. 1994;7:881-7.

5. Forno E, Celedon JC. Health disparities in asthma. Am J Respir Crit Care Med. 2012;185(10):1033-5.

6. Celedon JC, Roman J, Schraufnagel DE, Thomas A, Samet J. Respiratory health equality in the United States. The American thoracic society perspective. Ann Am Thorac Soc. 2014;11(4):473-9.

7. Moorman JE, Akinbami LJ, Bailey CM, Zahran HS, King ME, Johnson CA, Liu X. National Surveillance of Asthma: United States, 2001-2010. Vital Health Stat 3. 2012;(35):1-58

8. Flores C, Ma S-F, Pino-Yanes M, Wade MS, Pérez-Méndez L, Kittles RA, Wang D, Papaiahgari S, Ford JG, Kumar R, et al. African ancestry is associated with asthma risk in African Americans. PloS One. 2012;7:e26807.

9. Lester LA, Rich SS, Blumenthal MN, Togias A, Murphy S, Malveaux F, Miller ME, Dunston GM, Solway J, Wolf RL, et al. Ethnic differences in asthma and associated phenotypes: collaborative study on the genetics of asthma. J Allergy Clin Immunol. 2001;108:357-62.

10. Torgerson DG, Ampleford EJ, Chiu GY, Gauderman WJ, Gignoux CR, Graves PE, Himes BE, Levin AM, Mathias RA, Hancock DB, et al. Meta-analysis of genome-wide association studies of asthma in ethnically diverse North American populations. Nat Genet. 2011;43(9):887-92.

11. Desai M, Oppenheimer JJ. Medication adherence in the asthmatic child and adolescent. Curr Allergy Asthma Rep. 2011;11(6):454-64.

12. Apter AJ, Wan F, Reisine S, Bender B, Rand C, Bogen DK, Bennett IM, BryantStephens T, Roy J, Gonzalez R, et al. The association of health literacy with adherence and outcomes in moderate-severe asthma. J Allergy Clin Immunol. 2013;132(2):321-7.

13. Fiscella K, Franks P, Gold MR, Clancy CM. Inequality in quality: addressing socioeconomic, racial, and ethnic disparities in health care. JAMA. 2000; 283(19):2579-84.

14. House J, Williams D. Understanding and reducing socioeconomic and racial/ethnic disparities in health. In: Syme BDSSL, editor. Promoting health: Intervention strategies from social and behavioral research. Washington, DC: National Academy Press; 2000. p. 81-125.

15. Povich D, Roberts B, Mather M. Low-income working families: the racial/ ethnic divide. The working poor families project policy brief 2015, winter 2014-2015. http://www.workingpoorfamilies.org/wp-content/uploads/2015/ 03/WPFP-2015-Report_Racial-Ethnic-Divide.pdf. Accessed 10 Jan 2017.

16. Mokdad AH. The Behavioral Risk Factors Surveillance System: past, present, and future. Annu Rev Public Health. 2009:30:43-54.

17. Stein $A D$, Lederman $\mathrm{Rl}$, Shea $\mathrm{S}$. The behavioral risk factor surveillance system questionnaire: its reliability in a statewide sample. Am J Public Health. 1993; 83(12):1768-72.

18. Nelson DE, Holtzman D, Bolen J, Stanwyck CA, Mack KA. Reliability and validity of measures from the Behavioral Risk Factor Surveillance System (BRFSS). Soz Praventivmed. 2001;46 Suppl 1:S3-42.

19. Ezzati M, Martin H, Skjold S, Vander Hoorn S, Murray CJ. Trends in national and state-level obesity in the USA after correction for self-report bias: analysis of health surveys. J R Soc Med. 2006;99(5):250-7.
20. Arday DR, Tomar SL, Nelson DE, Merritt RK, Schooley MW, Mowery P. State smoking prevalence estimates: a comparison of the Behavioral Risk Factor Surveillance System and current population surveys. Am J Public Health. 1997:87(10):1665-9.

21. Nelson DE, Naimi TS, Brewer RD, Bolen J, Wells HE. Metropolitan-area estimates of binge drinking in the United States. Am J Public Health. 2004; 94(4):663-71.

22. Jia H, Link M, Holt J, Mokdad AH, Li L, Levy PS. Monitoring county-level vaccination coverage during the 2004-2005 influenza season. Am J Prev Med. 2006;31(4):275-80.

23. Zahran HS, Bailey C. Factors associated with asthma prevalence among racial and ethnic groups-United States, 2009-2010 behavioral risk factor surveillance system. J Asthma. 2013:50(6):583-9.

24. Gwynn RC. Risk factors for asthma in US adults: results from the 2000 Behavioral Risk Factor Surveillance System. J Asthma. 2004;41(1):91-8.

25. Strine TW, Ford ES, Balluz L, Chapman DP, Mokdad AH. Risk behaviors and health-related quality of life among adults with asthma: the role of mental health status. Chest. 2004;126(6):1849-54.

26. Ford ES, Mannino DM, Homa DM, Gwynn C, Redd SC, Moriarty DG, Mokdad $\mathrm{AH}$. Self-reported asthma and health-related quality of life: findings from the behavioral risk factor surveillance system. Chest. 2003;123(1):119-27.

27. Centers for Disease Control and Prevention (CDC). National Center for Health Statistics (NCHS). National health and nutrition examination survey data. http://www.cdc.gov/nchs/nhanes/index.htm. Accessed 10 Jan 2017.

28. Han YY, Forno E, Celedon JC. Adiposity, fractional exhaled nitric oxide, and asthma in U.S. children. Am J Respir Crit Care Med. 2014;190(1):32-9.

29. Malinovschi A, Fonseca JA, Jacinto T, Alving K, Janson C. Exhaled nitric oxide levels and blood eosinophil counts independently associate with wheeze and asthma events in National Health and Nutrition Examination Survey subjects. J Allergy Clin Immunol. 2013;132(4):821-7. e821-825.

30. Wells EM, Dearborn DG, Jackson LW. Activity change in response to bad air quality, National Health and Nutrition Examination Survey, 2007-2010. PLoS One. 2012;7(11)

31. See KC, Christiani DC. Normal values and thresholds for the clinical interpretation of exhaled nitric oxide levels in the US general population: results from the National Health and Nutrition Examination Survey 20072010. Chest. 2013;143(1):107-16.

32. R Development Core Team. R: A Language and Environment for Statistical Computing. Vienna: R Foundation for Statistical Computing; 2016.

33. Baffi CW, Wood L, Winnica D, Strollo PJ, Gladwin MT, Que LG, Holguin F. Metabolic Syndrome and the Lung. Chest. 2016;149(6):1525-34.

34. Kim S-H, Sutherland ER, Gelfand EW. Is there a link between obesity and asthma? Allergy, Asthma Immunol Res. 2014;6:189-95.

35. Sutherland ER. Linking obesity and asthma. Ann N Y Acad Sci. 2014;1311:31-41.

36. Papoutsakis C, Priftis KN, Drakouli M, Prifti S, Konstantaki E, Chondronikola M, Antonogeorgos G, Matziou V. Childhood overweight/obesity and asthma: is there a link? A systematic review of recent epidemiologic evidence. J Acad Nutr Diet. 2013;113:77-105.

37. Beuther DA, Sutherland ER. Overweight, obesity, and incident asthma: a meta-analysis of prospective epidemiologic studies. Am J Respir Crit Care Med. 2007;175:661-6.

38. Chen YC, Dong GH, Lin KC, Lee YL. Gender difference of childhood overweight and obesity in predicting the risk of incident asthma: a systematic review and meta-analysis. Obes Rev. 2013;14:222-31.

39. Scherer PE. Adipose tissue: from lipid storage compartment to endocrine organ. Diabetes. 2006;55(6):1537-45.

40. Akinbami $L$ J, Fryar $C D$. Asthma prevalence by weight status among adults: United States, 2001-2014. NCHS data brief, no 239. Hyattsville: National Center for Health Statistics; 2016.

41. Perret JL, Dharmage SC, Matheson MC, Johns DP, Gurrin LC, Burgess JA, Marrone J, Markos J, Morrison S, Feather I, et al. The interplay between the effects of lifetime asthma, smoking, and atopy on fixed airflow obstruction in middle age. Am J Respir Crit Care Med. 2013;187:42-8.

42. Polosa R, Thomson NC. Smoking and asthma: dangerous liaisons. Eur Respir J. 2013;41:716-26.

43. Simon PA, Zeng Z, Wold CM, Haddock W, Fielding JE. Prevalence of childhood asthma and associated morbidity in Los Angeles County: impacts of race/ethnicity and income. J Asthma. 2003:40:535-43.

44. Ennis S, Rios-Vargas M, Albert N. The Hispanic Population: 2010. 2010 Census Briefs. 2011. http://www.census.gov/prod/cen2010/briefs/c2010br-04. pdf. Accessed 10 Jan 2017 
45. Smith LA, Hatcher-Ross JL, Wertheimer R, Kahn RS. Rethinking race/ ethnicity, income, and childhood asthma: racial/ethnic disparities concentrated among the very poor. Public Health Rep (Washington, DC: 1974). 2005;120:109-16

46. Claudio L, Stingone JA, Godbold J. Prevalence of childhood asthma in urban communities: the impact of ethnicity and income. Ann Epidemiol. 2006;16:332-40.

47. Spencer N, Thanh TM, Louise S. Low income/socio-economic status in early childhood and physical health in later childhood/adolescence: a systematic review. Matern Child Health J. 2013;17:424-31.

48. von Mutius E. Gene-environment interactions in asthma. J Allergy Clin Immunol. 2009;123:3-11. quiz 12-13.

49. Sarpong SB, Hamilton RG, Eggleston PA, Adkinson NF. Socioeconomic status and race as risk factors for cockroach allergen exposure and sensitization in children with asthma. J Allergy Clin Immunol. 1996:97:1393-401.

50. Kozyrskyj AL, Kendall GE, Jacoby P, Sly PD, Zubrick SR. Association between socioeconomic status and the development of asthma: analyses of income trajectories. Am J Public Health. 2010;100:540-6.

51. Apter AJ, Bryant-Stephens T, Morales KH, Wan F, Hardy S, Reed-Wells S, Dominguez M, Gonzalez R, Mak N, Nardi A et al. Using IT to improve access, communication, and asthma in African American and Hispanic/Latino Adults: Rationale, design, and methods of a randomized controlled trial. Contemp Clin Trials. 2015.

52. Pierannunzi C, Hu SS, Balluz L. A systematic review of publications assessing reliability and validity of the Behavioral Risk Factor Surveillance System (BRFSS), 2004-2011. BMC Med Res Methodol. 2013;13:49.

53. Humes K, Jones N, Ramirez R. Overview of Race and Hispanic Origin: 2010. 2010 Census Briefs. 2011. http://www.census.gov/prod/cen2010/briefs/ c2010br-02.pdf. Accessed 10 Jan 2017.

54. Ryan C, Bauman K. Education Attainment in the United States: 2015. In: Population Characteristics. 2016. http://www.census.gov/content/dam/ Census/library/publications/2016/demo/p20-578.pdf. Accessed 10 Jan 2017.

55. Posey K. Household Income: 2015. American Community Survey Briefs. 2016. http://www.census.gov/content/dam/Census/ibrary/publications/ 2016/demo/acsbr15-02.pdf. Accessed 10 Jan 2017.

\section{Submit your next manuscript to BioMed Central and we will help you at every step:}

- We accept pre-submission inquiries

- Our selector tool helps you to find the most relevant journal

- We provide round the clock customer support

- Convenient online submission

- Thorough peer review

- Inclusion in PubMed and all major indexing services

- Maximum visibility for your research

Submit your manuscript at www.biomedcentral.com/submit 